\title{
(2) OPEN ACCESS \\ Update on management of atrial fibrillation in heart failure: a focus on ablation
}

\author{
Bart A Mulder (1) , Michiel Rienstra, Isabelle C Van Gelder (ㄷ), Yuri Blaauw
}

Department of Cardiology, University Medical Center Groningen, Groningen, The Netherlands

\section{Correspondence to} Dr Bart A Mulder, University Medical Center Groningen, Groningen 9713 GZ, The Netherlands;

b.a.mulder@umcg.nl

Received 11 February 2021 Accepted 21 May 2021
Check for updates

(C) Author(s) (or their employer(s)) 2021. Re-use permitted under CC BY-NC. No commercial re-use. See rights and permissions. Published by BMJ.

To cite: Mulder BA, Rienstra M, Van Gelder IC, et al. Heart Epub ahead of print: [please include Day Month Year]. doi:10.1136/ heartjnl-2020-318081

\begin{abstract}
Atrial fibrillation is increasingly encountered in patients with heart failure. Both diseases have seen tremendous rises in incidence in recent years. In general, the treatment of atrial fibrillation is focused on relieving patients from atrial fibrillation-related symptoms and risk reduction for thromboembolism and the occurrence or worsening of heart failure. Symptomatic relief may be accomplished by either (non-)pharmacological rate or rhythm control in combination with optimal therapy of underlying cardiovascular morbidities and risk factors. Atrial fibrillation ablation has been performed in patients without overt heart failure successfully for many years. However, in recent years, attempts have been made for patients with heart failure as well. In this review, we discuss the current literature describing the treatment of atrial fibrillation in heart failure. We highlight the early rate versus rhythm control studies, the importance of addressing underlying conditions and treatment of risk factors. A critical evaluation will be performed of the catheter ablation studies that have been performed so far in light of larger (post-hoc) ablation studies. Furthermore, we will hypothesise the role of patient selection as next step in optimising outcome for patient with atrial fibrillation and heart failure.
\end{abstract}

\section{INTRODUCTION}

Atrial fibrillation (AF) and heart failure (HF) frequently coexist and influence progression of the other. ${ }^{1-3} \mathrm{~A}$ common adopted concept is that $\mathrm{AF}$ begets HF and HF begets AF due to shared pathophysiological mechanisms and risk factors. ${ }^{45}$ The combination of these diseases may subsequently increase the risk of stroke, dementia, HF hospitalisation and all-cause mortality. ${ }^{256}$ Early intervention is suggested to halt the progress of both diseases and improve prognosis. ${ }^{267}$ Recent European Society of Cardiology AF guidelines suggest that treatment of underlying conditions is pivotal and treatment should have a holistic approach (figure 1). ${ }^{2}$ Therefore, identification and treatment of risk factors should be key elements in $\mathrm{AF}$ treatment. ${ }^{8-11}$ This is even more of importance in patients with $\mathrm{HF}$ as AF negatively influences prognosis. ${ }^{5}$ In patients with HF, AF treatment options are limited; most antiarrhythmic drugs (AADs) are contraindicated or poorly tolerated. ${ }^{26}$ Amiodarone is effective but there is hesitation to use it, especially in young patients due to side-effects. ${ }^{26}$ Early targeted therapy of underlying conditions and risk factors in early persistent $\mathrm{AF}$ and moderately stable HF has been shown to improve sinus rhythm maintenance at 1 year. $^{7}$ Also, long-term sustained weight loss in combination with optimal therapy of underlying heart diseases and risk factors is associated with significant reduction of AF burden and maintenance of long-term sinus rhythm, although these patients had no HF. ${ }^{9-12}$ Focus of AF rhythm control therapy has shifted towards catheter ablation. Several studies have shown that pulmonary vein isolation (PVI) with or without additional left atrial ablation may improve outcomes. ${ }^{13-20}$ Therefore, in this review, we evaluate the current treatment of AF in patients with HF, both with preserved (HFpEF) and reduced ejection fraction (HFrEF).

\section{AF and HF}

$\mathrm{AF}$ and $\mathrm{HF}$ are two entities which clinically may present alone but often are encountered together. ${ }^{4}$ $\mathrm{AF}$ and HF share many risk factors such as hypertension, obesity, diabetes mellitus and ischaemic heart disease. ${ }^{12}$ Due to these comorbidities and AF itself, an 'atrial cardiomyopathy' can develop as a consequence of the structural, architectural, contractile and electrophysiological changes that occur in the atria. ${ }^{21}$ The development of AF or HF first is of interest as the chronology of the diseases may impact prognosis. HF first seems to infer an inferior prognosis. ${ }^{22} \mathrm{AF}$, on the other hand, may contribute to the development of HF by several mechanisms. ${ }^{23}$ During AF, loss of atrial systole reduces left ventricular (LV) filling and may reduce cardiac output by $25 \% .{ }^{23}$ Also, the irregularity and a too high heart rate during $\mathrm{AF}$ may increase the likelihood to develop LV dysfunction even leading to a reversible form of (tachy)cardiomyopathy. ${ }^{24}$ This is illustrated in patients who develop LV dysfunction during AF and show a recovery of LV ejection fraction (LVEF) after restoration of sinus rhythm. ${ }^{1625}$ Thus, AF is of importance in the development and maintenance of LV dysfunction and, therefore, should be taken into account for every patient presenting with HF (figure 1).

\section{Clinical presentation of AF in $\mathrm{HF}$}

Key elements in diagnosing HF are signs and symptoms of HF and reduced LVEF. It, however, is often difficult to diagnose $\mathrm{HFpEF}$ in patients with $\mathrm{AF}^{26}$ This is due to a large overlap in signs and symptoms. ${ }^{26}$ For example, breathlessness and fatigue are important symptoms in HF but may also be found in AF without diagnosed or recognised HF. A recent white paper suggested some signs and investigations to use in clinical practice. ${ }^{26}$

\section{AF treatment in the setting of $\mathrm{HF}$}

Pharmacological rhythm control is especially difficult in patients with HFrEF. ${ }^{2}$ Most AADs cannot be instituted because of their negative inotropic effects. Amiodarone is the only AAD approved for HFrEF but is unfortunately associated with many 


\begin{tabular}{|l|l|l|}
\hline Step 1 & Assess and treat risk factors \& co-morbidities \\
\hline Step 2 & Initiate medical treatment based on current guidelines \\
\hline & AFrEF & $\begin{array}{l}\text { ACE-I, ARB, MRA, statin in patients with risk factors, left } \\
\text { ventricular hypertrophy or left ventricular dysfunction }\end{array}$ \\
\hline Step 3 & HFpEF & Discuss options: medical therapy or catheter ablation \\
\hline & HFrEF & $\begin{array}{l}\text { Catheter ablation should be considered to improve survival and } \\
\text { reduce heart failure hospitalization (Class Ila) }\end{array}$ \\
\hline Step 4 & & \\
\hline
\end{tabular}

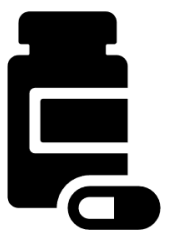

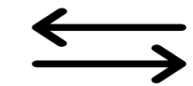

Re-assess if recurrence of AF

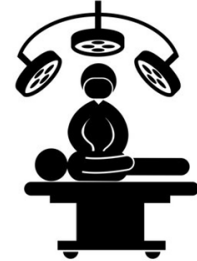

Catheter ablation HFrEF HFpEF TCM First line

After failure of drug therapy

Figure 1 Overview of long-term rhythm control in patient with heart failure. ACE-I, ACE inhibitor; AF, atrial fibrillation; ARB, angiotensin II receptor blocker; ARNI, angiotensin receptor-neprilysin inhibitor; HFpEF, heart failure with preserved ejection fraction; HFrEF, heart failure with reduced ejection fraction; MRA, mineralocorticoid receptor antagonists; SGLT2i, sodium-glucose co-transporter-2 inhibitors; TCM, tachycardiomyopathy.

adverse effects. ${ }^{2}$ Therefore, rate versus rhythm strategies were performed to assess whether there was any benefit for rhythm control. Noteworthy, these trials were performed before the era of ablation (table 1). ${ }^{27-31}$ The largest trial that studied rate versus rhythm control trial in patients with $\mathrm{HF}$, the AF and congestive heart failure (AF-CHF) trial, included 1376 patients with LVEF of $35 \%$ or lower and randomised to a rate or pharmacological rhythm control strategy. ${ }^{30}$ No differences were observed in allcause mortality or secondary outcomes (death from any cause, worsening HF or stroke). ${ }^{30}$ In the recent Routine vs Aggressive risk factor driven upstream rhythm Control for prevention of Early atrial fibrillation in heart failure (RACE 3 ) trial included

Table 1 Overview of rate versus rhythm analysis investigating atrial fibrillation (AF) treatment in the setting of heart failure (HF) before the ablation era

\begin{tabular}{|c|c|c|c|c|c|c|c|c|c|c|c|}
\hline Study & $\begin{array}{l}\text { No of } \\
\text { patients }\end{array}$ & $\begin{array}{l}\text { Mean } \\
\text { age }\end{array}$ & Women & $\begin{array}{l}\text { Persistent } \\
\text { AF }\end{array}$ & $\begin{array}{l}\text { Inclusion } \\
\text { criteria }\end{array}$ & Endpoint & Comparison & PVI & $\begin{array}{l}\text { Comorbidity } \\
\text { treatment }\end{array}$ & $\begin{array}{l}\text { Follow-up } \\
\text { (years) }\end{array}$ & Outcome \\
\hline \multicolumn{12}{|c|}{ Rate versus rhythm trials } \\
\hline DIAMOND-CHF $^{27}$ & 1518 & 70 & $26.6 \%$ & $100 \%$ & $\begin{array}{l}\text { NYHA III/ } \\
\text { IV and LVEF } \\
<35 \%\end{array}$ & Mortality & $\begin{array}{l}\text { Dofetilide } \\
\text { versus placebo }\end{array}$ & $0 \%$ & Not specified & 1.5 & $\begin{array}{l}\text { No effect } \\
\text { on mortality } \\
\text { ( } p=n s)\end{array}$ \\
\hline RACE-HF ${ }^{28}$ & 261 & 69 & $35 \%$ & $100 \%$ & NYHA II/III & $\begin{array}{l}\text { Composite of } \\
\text { mortality and } \\
\text { hospitalisation }\end{array}$ & $\begin{array}{l}\text { Rate versus } \\
\text { rhythm }\end{array}$ & $0 \%$ & Not specified & 2.3 & $\begin{array}{l}\text { Rate } \\
\text { control is } \\
\text { not inferior } \\
\text { to rhythm } \\
\text { control } \\
\text { ( } p=n s)\end{array}$ \\
\hline AFFIRM-HF ${ }^{29}$ & 788 & N/A & $25 \%$ & Recurrent AF & LVEF $<50 \%$ & $\mathrm{ACM}$ & $\begin{array}{l}\text { Rate versus } \\
\text { rhythm }\end{array}$ & $0 \%$ & Not specified & 3.5 & $\begin{array}{l}\text { No effect } \\
\text { on mortality } \\
\text { ( } p=n s)\end{array}$ \\
\hline $\mathrm{AF}-\mathrm{CHF}^{30}$ & 1376 & 67 & $18 \%$ & $68.5 \%$ & LVEF $<35 \%$ & $\begin{array}{l}\text { Cardiovascular } \\
\text { death }\end{array}$ & $\begin{array}{l}\text { Rate versus } \\
\text { rhythm }\end{array}$ & $0 \%$ & Not specified & 3.1 & $\begin{array}{l}\text { No effect } \\
\text { on mortality } \\
\text { ( } p=n s)\end{array}$ \\
\hline
\end{tabular}


Table 2 Overview of recent (ablation) studies for the treatment of atrial fibrillation (AF) in the setting of heart failure (HF)

\begin{tabular}{|c|c|c|c|c|c|c|c|c|c|c|}
\hline Study & $\begin{array}{l}\text { No of } \\
\text { patients }\end{array}$ & $\begin{array}{l}\text { Mean } \\
\text { age }\end{array}$ & Women & $\begin{array}{l}\text { Inclusion } \\
\text { criteria }\end{array}$ & Endpoint & Comparison & PVI & $\begin{array}{l}\text { Comorbidity } \\
\text { treatment }\end{array}$ & $\begin{array}{l}\text { Follow-up } \\
\text { (years) }\end{array}$ & Outcome \\
\hline \multicolumn{11}{|c|}{ Recent AF ablation trials } \\
\hline PABA-CHF ${ }^{13}$ & 81 & 60 & $8 \%$ & $\begin{array}{l}\text { NYHA III/IV and } \\
\text { LVEF }<40 \%\end{array}$ & $\begin{array}{l}\text { Composite of } \\
\text { QOL, LVEF, 6- } \\
\text { MWT }\end{array}$ & $\begin{array}{l}\text { PVI versus AVN } \\
\text { ablation }\end{array}$ & $51 \%$ & Not specified & 0.5 & $\begin{array}{l}\text { PVI was superior } \\
(p<0.001)\end{array}$ \\
\hline MacDonald et a $\left.\right|^{15}$ & 41 & 63 & $22 \%$ & $\begin{array}{l}\text { NYHA II (11\%)/ } \\
\text { III (89\%) and } \\
\text { LVEF <35\% }\end{array}$ & Change in LVEF & $\begin{array}{l}\text { PVI versus rate } \\
\text { control (digoxin) }\end{array}$ & $54 \%$ & Not specified & 0.5 or 0.75 & $\begin{array}{l}\text { PVI did not } \\
\text { improve LVEF } \\
(p=n s)\end{array}$ \\
\hline ARC-HF ${ }^{17}$ & 52 & 63 & $13 \%$ & $\begin{array}{l}\text { NYHA II-IV and } \\
\text { LVEF }<35 \%\end{array}$ & $\begin{array}{l}\text { 12-month change } \\
\text { in peak oxygen } \\
\text { consumption }\end{array}$ & $\begin{array}{l}\text { PVI versus rate } \\
\text { control }\end{array}$ & $50 \%$ & Not specified & 1.0 & $\begin{array}{l}\text { PVI was superior } \\
(p=0.018)\end{array}$ \\
\hline CAMTAF $^{18}$ & 50 & 57 & $4 \%$ & $\begin{array}{l}\text { NYHA II (46\%)/ } \\
\text { III (54\%) and } \\
\text { LVEF }<50 \%\end{array}$ & Difference in LVEF & $\begin{array}{l}\text { PVI versus rate } \\
\text { control }\end{array}$ & $52 \%$ & Not specified & 1.0 & $\begin{array}{l}\text { PVI was superior } \\
(p=0.015)\end{array}$ \\
\hline AATAC ${ }^{16}$ & 203 & 61 & $26 \%$ & $\begin{array}{l}\text { NYHA II-IV and } \\
\text { LVEF }<40 \%\end{array}$ & Recurrence of AF & $\begin{array}{l}\text { PVI versus } \\
\text { amiodarone }\end{array}$ & $50 \%$ & Not specified & 2.0 & $\begin{array}{l}\text { PVI was superior } \\
(p<0.0001)\end{array}$ \\
\hline CAMERA-MRII ${ }^{19}$ & 68 & 61 & $9 \%$ & LVEF $<45 \%$ & Change in LVEF & $\begin{array}{l}\text { PVI versus rate } \\
\text { control }\end{array}$ & $50 \%$ & Not specified & 0.5 & $\begin{array}{l}\text { PVI was superior } \\
(p<0.0001)\end{array}$ \\
\hline CASTLE-AF ${ }^{14}$ & 363 & 64 & $14 \%$ & $\begin{array}{l}\text { NYHA I-IV (11\%, } \\
58 \%, 27 \%, 1 \%) \\
\text { and LVEF <35\% }\end{array}$ & $\begin{array}{l}\text { Composite of } \\
\text { ACM of HF } \\
\text { hospitalisation }\end{array}$ & $\begin{array}{l}\text { PVI versus } \\
\text { medical therapy } \\
\text { (rhythm or rate } \\
\text { control) }\end{array}$ & $49 \%$ & Not specified & 3.1 & $\begin{array}{l}\text { PVI was superior } \\
(p=0.007)\end{array}$ \\
\hline $\begin{array}{l}\text { CABANA-HF (post- } \\
\text { hoc) }\end{array}$ & 778 & 68 & $44 \%$ & $\begin{array}{l}\text { NYHA II-IV } \\
(76 \%, 23 \%, 1 \%)\end{array}$ & $\begin{array}{l}\text { Composite of } \\
\text { ACM, stroke, } \\
\text { bleeding, CA }\end{array}$ & $\begin{array}{l}\text { PVI versus } \\
\text { medical therapy } \\
\text { (rhythm or rate } \\
\text { control) }\end{array}$ & $49 \%$ & Not specified & 4.0 & $\begin{array}{l}\text { PVI was superior } \\
\text { ( } p=\text { significant) }\end{array}$ \\
\hline \multicolumn{11}{|c|}{ Recent AF trials (overall results) } \\
\hline RACE $3^{7}$ & 245 & 64 & $21 \%$ & $\begin{array}{l}\text { HFrEF=NYHA } \\
\text { I-III and LVEF } \\
<45 \% . \\
\text { HFpEF=NYHA } \\
\text { II-III and LVEF } \\
>45 \%\end{array}$ & $\begin{array}{l}\text { Sinus rhythm on } \\
\text { 7-day Holter }\end{array}$ & $\begin{array}{l}\text { Targeted therapy } \\
\text { of underlying } \\
\text { conditions } \\
\text { versus } \\
\text { conventional } \\
\text { (causal } \\
\text { treatment of AF } \\
\text { and HF+rhythm } \\
\text { control) }\end{array}$ & N/A & Targeted therapy & 1.0 & $\begin{array}{l}\text { Targeted therapy } \\
\text { was superior } \\
\text { ( } \mathrm{p}=0.042 \text { ) } \\
\text { at } 1 \text { year; no } \\
\text { differences at } 5 \\
\text { years }\end{array}$ \\
\hline EAST-AFNET $4^{40}$ & 2789 & 70 & $46 \%$ & $\begin{array}{l}\text { Stable heart } \\
\text { failure }(n=798 \\
(28.6 \%))^{*}\end{array}$ & $\begin{array}{l}\text { Composite of } \\
\text { death from CV } \\
\text { causes, stroke, } \\
\text { hospitalisation for } \\
\text { HF or ACS }\end{array}$ & $\begin{array}{l}\text { Early rhythm } \\
\text { control or usual } \\
\text { care (initial rate } \\
\text { control, in case } \\
\text { of symptoms } \\
\text { mitigation to } \\
\text { rhythm control) }\end{array}$ & $13 \%$ & $\begin{array}{l}\text { According to } \\
\text { guidelines }\end{array}$ & 5.1 & $\begin{array}{l}\text { Early rhythm } \\
\text { control was } \\
\text { superior } \\
(p=0.005)\end{array}$ \\
\hline
\end{tabular}

\footnotetext{
*No subgroup data available yet.

ACM, all-cause mortality; ACS, acute coronary syndrome; AVN, AV nodal ablation; $C A$, cardiac arrest; $C V$, cardiovascular; HFpEF, HF with preserved ejection fraction; HFrEF, HF with reduced ejection fraction; LVEF, left ventricular ejection fraction; 6-MWT, 6-minute walk test; N/A, not available; NYHA, New York Heart Association; PVI, pulmonary vein isolation; QOL, quality of life.
}

stable patients with HFpEF and HFrEF with early persistent $\mathrm{AF}$ who were randomised either to targeted therapy of underlying conditions plus rhythm control or routine rhythm control therapy (table 2). ${ }^{32}$ AAD treatment was instituted after recurrent AF and was effective in half of the patients at 1 year. ${ }^{32}$ Amiodarone was the most effective drug, but unfortunately, again limited by adverse effects. Ablation was performed only in a limited number of patients.

\section{PVI in patients with $\mathrm{HF}$}

In the field of catheter ablation in HF, several trials have been conducted. ${ }^{13-19}$ Important to note is that initial series were often single-centre studies that included a limited number of patients (41-81 patients) with limited follow-up (6-12 months) and had surrogate outcomes such as improvement in LVEF or exercise tolerance (table 2, figure 2). More recently, larger trials with substantial longer duration of follow-up and cardiovascular endpoints as well as sinus rhythm maintenance have been conducted. ${ }^{1416}$ The Pulmonary vein antrum isolation vs AV node ablation with Bi-ventricular pacing for treatment of Atrial fibrillation in patients with Congestive Heart Failure (PABA-CHF) was among the first trials to investigate the efficacy of PVI in patients with HFrEF. ${ }^{13}$ PABA-CHF compared the most definitive approach to achieve rate control, atrioventricular node ablation, with PVI. After 6 months of follow-up, the composite endpoint was in favour of PVI. ${ }^{13}$ Several small trials compared PVI with pharmacological rate control. A small study with only 41 patients compared PVI versus rate control (if heart rate was above 80 beats/ min, digoxin was added) with change in LVEF as the primary endpoint. The study was underpowered to detect any difference in the LVEF change. ${ }^{15}$ Two other trials compared PVI with pharmacological rate control. ${ }^{17}{ }^{18}$ Both were small studies (52 and 50 


\begin{tabular}{|c|c|c|c|c|c|c|c|c|c|}
\hline & \multicolumn{9}{|c|}{ Percentage success of ablation strategy } \\
\hline & 90 & & & & & & & & \\
\hline & 80 & & & & & & & & \\
\hline & 70 & & & & & & & & \\
\hline & 60 & & & & & & & & \\
\hline & 50 & & & & & & & & \\
\hline & 40 & & & & & & & & \\
\hline & 30 & & & & & & & & \\
\hline & 20 & & & & & & & & \\
\hline & 10 & & & & & & & & \\
\hline No f patients & 0 & 81 & 41 & 52 & 50 & & 68 & 363 & 778 \\
\hline No. of patients & & 6 & $\frac{41}{6}$ & $\frac{32}{12}$ & $\frac{50}{12}$ & 203 & $\frac{60}{6}$ & & \\
\hline Median follow-up in months & & 6 & 6 & 12 & 12 & 24 & 6 & 37 & 48 \\
\hline AF ablation strategy & & $\begin{array}{l}\mathrm{PVI} \pm \text { linear } \\
\text { lines }\end{array}$ & $\begin{array}{l}\mathrm{PVI} \pm \text { linear } \\
\text { lines }\end{array}$ & $\begin{array}{l}\text { Step wise } \\
\text { approach }\end{array}$ & $\begin{array}{l}\mathrm{PVI} \pm \text { linear } \\
\text { lines } \pm \text { CFAE }\end{array}$ & $\begin{array}{l}\mathrm{PVI} \pm \text { linear } \\
\text { lines } \pm \mathrm{CFAE}\end{array}$ & $\begin{array}{l}\mathrm{PVI} \pm \text { linear } \\
\text { lines }\end{array}$ & $\begin{array}{l}\mathrm{PVI} \pm \text { linear } \\
\text { lines }\end{array}$ & $\begin{array}{l}\mathrm{PVI} \pm \text { linear } \\
\text { lines } \pm \mathrm{CFAE}\end{array}$ \\
\hline Ischaemic HF & & $73 \%$ & $50 \%$ & $33 \%$ & $26 \%$ & $62 \%$ & $0 \%$ & $46 \%$ & $22 \%$ (CAD) \\
\hline LVEF & & $27 \pm 8$ & $16 \pm 7$ & $22 \pm 8$ & $32 \pm 8$ & $29 \pm 5$ & $35 \pm 10$ & 33 (IQR 25-38) & $55(60-61)$ \\
\hline Persistent AF & & $51 \%$ & $100 \%$ & $100 \%$ & $100 \%$ & $100 \%$ & $72 \%$ & $70 \%$ & $55 \%$ \\
\hline Definition recurrence & & 30s of $\mathrm{AF} / \mathrm{AT}$ & AF occurrence & AF occurrence & 30s of AF/AT & AF occurrence & 30s of AF/AT & 30s of AF/AT & AF occurrence \\
\hline Year & & 2008 & 2011 & 2013 & 2014 & 2016 & 2017 & 2018 & 2021 \\
\hline Study & & PABA-CHF & MacDonald & ARC-HF & CAMTAF & AATAC & CAMERA-MRI & CASTLE-AF & CABANA-HF \\
\hline
\end{tabular}

Figure 2 Overview of catheter ablation studies in patients with heart failure (HF). AF, atrial fibrillation; $A T$, atrial tachycardia; $C A D$, coronary artery disease; CFAE, complex fragmented atrial electrograms; LVEF, left ventricular ejection fraction; PVI, pulmonary vein isolation.

patients) and had limited follow-up (12 and 6 months, respectively). ${ }^{1718}$ One showed that PVI was superior in increasing peak oxygen consumption after 12 months. ${ }^{17}$ The other trial showed a significant improvement in LVEF after 6 months of follow-up (table 2). ${ }^{18}$ Another recent small study included 68 patients and change in LVEF on repeat cardiac magnetic resonance (CMR) was the primary endpoint. ${ }^{19}$ Patients were randomised to either PVI or pharmacological rate control. After 6 months of follow-up, an improvement of LVEF was observed in those randomised to PVI. Of interest, restoration of sinus rhythm with PVI resulted in less fibrosis on CMR at 6 months as compared with rate control. These studies were pooled in several metaanalyses. $^{33} 34$ These meta-analyses showed that AF ablation was associated with improved all-cause mortality, exercise capacity and LV systolic function. Average LVEF improvement ranged between $11 \%$ and $13 \%$ illustrating the advantage of AF ablation. Improvement in LVEF was most pronounced in patients with non-ischaemic cardiomyopathy. The beneficial effects of catheter ablation on LVEF and 6-minute walk test were not observed in the very small randomised trial performed by MacDonald et al. ${ }^{15}$ In another trial, almost $90 \%$ of patients had New York Heart Association (NYHA) III HF as a sign of advanced disease with probably more severe atrial cardiomyopathy, prohibiting catheter ablation to effectively restore and maintain sinus rhythm. ${ }^{35}$ A larger multicentre trial randomised 203 patients to either amiodarone or PVI (figure 2, table 2). ${ }^{16}$ After a follow-up of 24 months, freedom of AF was higher in those randomised to PVI (70\% vs 34\%). Furthermore, PVI was associated with a reduction of unplanned hospitalisation and mortality. ${ }^{16}$ The most relevant ablation trial in AF and HF, the Catheter Ablation vs Standard Conventional Therapy in Patients with Left Ventricular Dysfunction and Atrial Fibrillation (CASTLE-AF) trial, randomised 363 patients to either PVI or medical therapy (rate or rhythm control). ${ }^{14}$ Median LVEF was 25\% (IQR 25\%-38\%, figure 2), 27\% had cardiac resynchronisation therapy (CRT). PVI was associated with a significantly lower rate of the composite endpoint ( $28.5 \%$ vs $44.6 \%, \mathrm{p}=0.007)$, especially for the patients in the lower NYHA classes. ${ }^{36}$ Furthermore, an AF burden below $50 \%$ after 6 months of catheter ablation was associated with an improved outcome. ${ }^{37}$ Two other trials were performed in which also patients with HF were included. The Catheter Ablation vs Antiarrhythmic Drug Therapy for Atrial Fibrillation (CABANA) trial randomised patients to either PVI or drug therapy (rate or rhythm control). This main trial results did not show that PVI was superior to drug therapy. Recently, the HF post-hoc analysis was published which did show an improved outcome in the PVI group (figure 2, table 2). ${ }^{38}$ Important to note is that the patients included in the CASTLE-AF and the post-hoc analysis of CABANA were different. In the CABANA analysis, only $9.3 \%$ of the patients had an LVEF $<40 \%$ and the median LVEF was $55 \%$ implying a population with $\mathrm{HFpEF}$ rather than a population with HFrEF. The patients included in the CASTLE-AF had HFrEF (LVEF <35\%) and a device (implantable cardioverterdefibrillator or CRT-D), whereas in CABANA HF was defined as NYHA functional class II or higher. This makes a direct comparison between these two trials challenging. Considering the difficulty of diagnosing $\mathrm{HFpEF}$ in the setting of $\mathrm{AF}$, the question remains to what extent the CABANA-HF patients actually had HFpEF and not symptoms attributable to AF. ${ }^{39}$ The EAST-AFNET 4 trial randomised patients with and without HF to early rhythm control versus usual care. ${ }^{40}$ All patients had a short history of AF ( $<1$ year), with one-third having their first episode of AF at inclusion. Notably, 1505 (53.9\%) patients were in sinus rhythm at baseline. In the early rhythm control group, 20\% underwent PVI and 46\% started AAD during 2 years of follow-up. Patients randomised to early rhythm control had a lower risk of the primary outcome of death, stroke and hospitalisations (28.5\% vs $44.6 \%)$. In EAST-AFNET 4, $28 \%$ of patients had stable HF (defined as NYHA functional class II or LVEF $<50 \%$ ). The post-hoc analysis of the patients with HF is not yet available.

\section{Implications}

The outcomes of these trials suggest that prolonged periods of sinus rhythm may result in improved LVEF, quality of life and prognosis in a selected group of patients with HF. Important to realise is that, for instance in CASTLE-AF, PVI had limited 


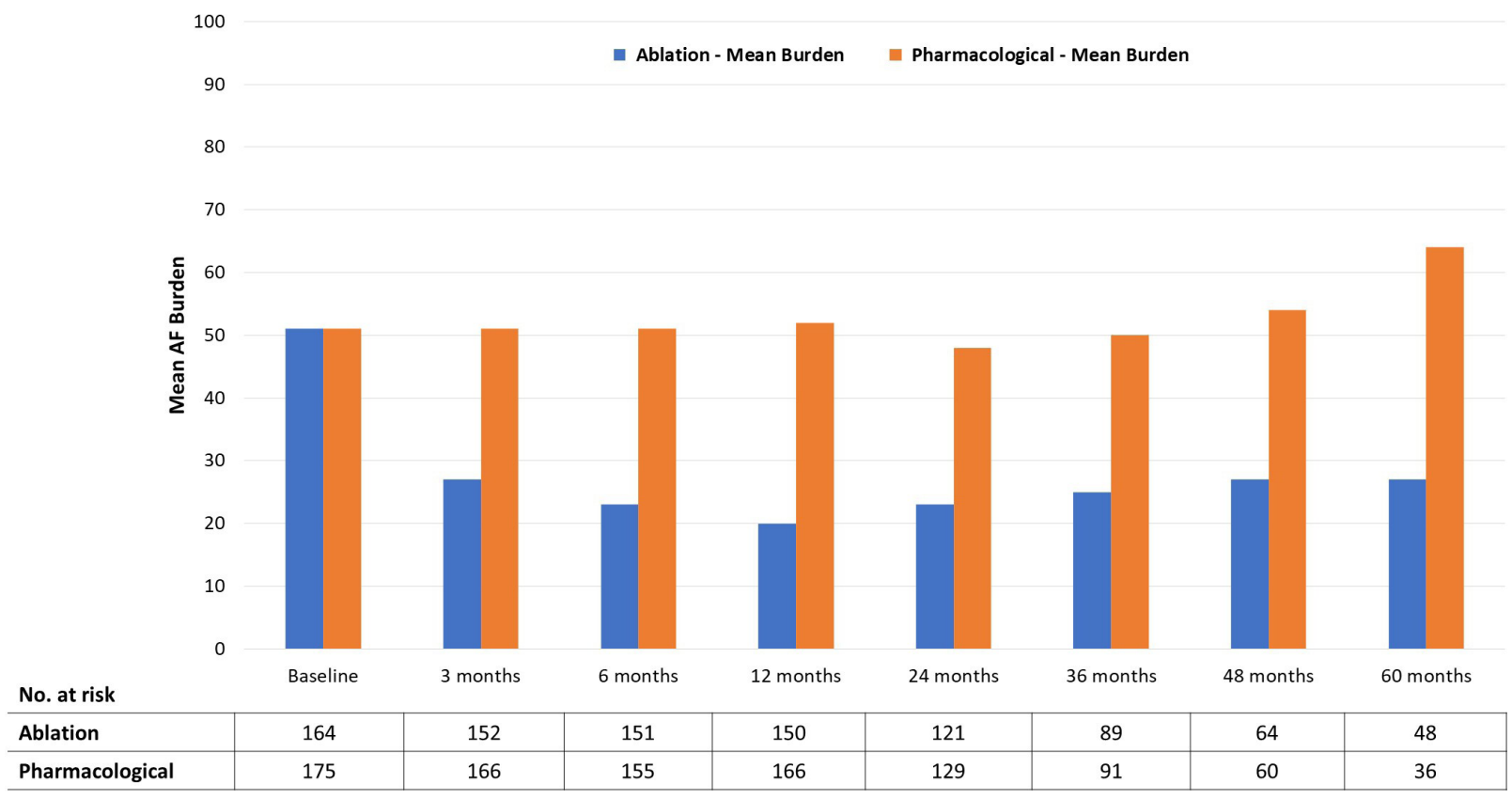

Figure 3 Mean atrial fibrillation (AF) burden in CASTLE-AF. Pharmacological groups consist of pharmacological rate or rhythm control.

success to maintain permanent long-term sinus rhythm. One of the proposed mechanisms behind the improvement in prognosis in the patients treated with PVI is that it significantly reduced total AF burden as is shown in figure $3 .{ }^{14}$ Post-hoc analysis showed that the risk for the primary endpoint was directly related to a low $(<50 \%)$ or high $(>50 \%) \mathrm{AF}$ burden at 6 months. ${ }^{37}$ Another potential explanation is that part of the patients had a tachycardiomyopathy. Longer periods of sinus rhythm may, therefore, be a mechanism to improve outcome eventually. Although the results of these trials are of interest, one important limitation is to appreciate that HF is often not defined comparably (table 2). ${ }^{41}$ In the CASTLE-AF, an LVEF of $<35 \%$ was considered HF; in the CABANA post-hoc analysis, an NYHA class of II or higher; and in EAST-AFNET 4, an LVEF $<50 \%$ (or NYHA functional class II). This once again underlines the difficulty of diagnosing HF and interpreting results of these relevant trials. Future trials clearly warrant collaboration between electrophysiology and HF specialists.

\section{Which ablation strategy to be used in patients with HF}

PVI is considered the cornerstone of catheter ablation for $\mathrm{AF}$, as no additional ablation options did show benefit so far. ${ }^{242}$ Moreover, in most trials, additional ablation (posterior wall isolation, linear lines or ablation of complex fractionated atrial electrograms) was up to the operator's discretion and was not investigated in a randomised way. There are even less data available for patients with HF. This is illustrated by ablation strategies used in CASTLE-AF. Of the 151 patients randomised to the ablation group, a PVI-only approach was performed in 74 patients. In the other 77 patients, the first AF ablation was PVI with additional lines or ablation of atrial electrograms (figure 3). ${ }^{14}$ It illustrates that different strategies are still performed as primary PVI approach. Currently there are several trials enrolling patients with HF in whom a single-shot device is used implying a PVI-only approach. For example, the Cryoballoon Ablation vs Medical Therapy in Patients With Heart Failure and Atrial Fibrillation (RACE-8-HF, NCT04342832) and the Ablation of Atrial Fibrillation in Heart Failure patients (CONTRA-HF, NCT03062241) both use a cryoballoon as PVI approach as compared with medical therapy (non-specified, guideline directed). These results are highly anticipated as, in contrast to previous trials, a homogeneous initial PVI approach is used. Other key future PVI elements of interest is to create durable endocardial lesions. High-power short duration ablation is a technique where the procedure time is significantly decreased as the applications (point-by-point) have been shortened by using higher wattage for a shorter period of time (ie, $50 \mathrm{~W}$ for $5-15$ s). ${ }^{43}{ }^{44}$ The advantage of high-power short duration may be that extensive left atrial ablations addressing more advanced substrate in patients with HF will become more feasible. Longterm follow-up seems promising; however, these techniques should be investigated in large randomised HF trials. ${ }^{43} 44$ There are several surgical AF ablation strategies: thoracoscopic (minimally invasive using radiofrequency clams onto the pulmonary veins), convergent (pericardioscopic epicardial posterior wall isolation) and hybrid ablation (combination of endocardial and epicardial ablation). ${ }^{24}$ Complications, however, should be taken into account for these more invasive procedures. Hybrid ablation strategies may improve outcome over single-staged surgical-only strategies, however, large randomised studies including patients with HF are definitely waited for. ${ }^{45-47}$ Clearly, future research endeavours should be performed into the field of high-power short duration, pulsed field ablation and hybrid/convergent AF ablation strategies in patients with AF and HF.

\section{Patient selection}

After addressing underlying cardiovascular conditions and treatment of risk factors, patients may be considered for catheter ablation according to the origin and severity of HF (figure 1). ${ }^{26}$ Presently, the number of patients with HF referred for catheter ablation is limited due to perceived higher complication rate and poor ablation outcome. Recent trials, however, demonstrate that AF ablation can be performed safely and long-term prognosis can improve, especially in patients with a tachycardiomyopathy, that is, without other demonstrable underlying heart disease. One of the main criticisms on the results of CASTLE-AF was that it was a selected population and therefore it is questionable 
whether the beneficial effects will also be observed if AF ablation is performed at a larger scale. ${ }^{48}$ Yet, there are some patients' characteristics which might guide whom will benefit from catheter ablation. Based on the post-hoc analysis of CASTLE-AF, patients with NYHA I/II and non-ischaemic aetiology of $\mathrm{HF}$ appear to benefit the most ${ }^{36}$ suggesting that early intervention might be beneficial. Adding RACE 3 data to this observation, it may suggest even a better outcome when targeted therapy of underlying conditions is implemented next to ablation. Considering the selection of patients who may benefit the most, the EAST-AFNET 4 trial makes a plea for patients with early AF. Furthermore, a surrogate marker for atrial cardiomyopathy (and advanced disease) is enlargement of the atria, therefore patients with enlarged atria or fibrosis on CMR are poorer candidates for catheter ablation. ${ }^{49}$ When in doubt whether patients may benefit from sinus rhythm, a trial of cardioversion usually with a short period of amiodarone use can be attempted to evaluate whether sinus rhythm may lead to improvement of functional class and LVEF. ${ }^{50}$

\section{CONCLUSIONS}

Treatment of AF starts with optimal medical therapy of HF and other underlying cardiovascular diseases, as illustrated in figure $1 .{ }^{26}$ As demonstrated by recent large randomised trials (early), rhythm control including PVI may reduce AF burden in patients with HF and improve sinus rhythm maintenance, and also may have prognostic implications, especially in those with a tachycardiomyopathy. Research and treatment of AF in patients with HF should focus on implementing treatment of risk factors and comorbidities, improving selection of patients that may benefit from ablation and finally improving efficacy of ablation including more durable transmural lesions in an optimised lesion set. Preferably, those trials are performed by a team of electrophysiology and HF specialists. Ultimately this may lead to an improved individualised treatment strategy for patients with AF and HF.

\section{Twitter Bart A Mulder@BA_Mulder}

Contributors All authors contributed to the drafting of the manuscript and approved the final contents.

Funding The authors have not declared a specific grant for this research from any funding agency in the public, commercial or not-for-profit sectors.

\section{Competing interests None declared.}

Patient and public involvement Patients and/or the public were not involved in the design, or conduct, or reporting, or dissemination plans of this research.

\section{Patient consent for publication Not required.}

Provenance and peer review Commissioned; externally peer reviewed.

Open access This is an open access article distributed in accordance with the Creative Commons Attribution Non Commercial (CC BY-NC 4.0) license, which permits others to distribute, remix, adapt, build upon this work non-commercially, and license their derivative works on different terms, provided the original work is properly cited, appropriate credit is given, any changes made indicated, and the use is non-commercial. See: http://creativecommons.org/licenses/by-nc/4.0/.

\section{ORCID iDs}

Bart A Mulder http://orcid.org/0000-0002-4411-3918

Isabelle C Van Gelder http://orcid.org/0000-0002-7579-1201

\section{REFERENCES}

1 Kotecha D, Chudasama R, Lane DA, et al. Atrial fibrillation and heart failure due to reduced versus preserved ejection fraction: a systematic review and meta-analysis of death and adverse outcomes. Int J Cardiol 2016;203:660-6.
2 Hindricks G, Potpara T, Dagres N, et al. 2020 ESC guidelines for the diagnosis and management of atrial fibrillation developed in collaboration with the European association for Cardio-Thoracic surgery (EACTS). Eur Heart J 2021;42:373-498.

3 Gorenek B, Halvorsen S, Kudaiberdieva G, et al. Atrial fibrillation in acute heart failure: a position statement from the Acute Cardiovascular Care Association and European Heart Rhythm Association of the European Society of Cardiology. Eur Heart J Acute Cardiovasc Care 2020;9:348-57.

4 Santhanakrishnan R, Wang N, Larson MG, et al. Atrial fibrillation begets heart failure and vice versa: temporal associations and differences in preserved versus reduced ejection fraction. Circulation 2016;133:484-92.

5 Wang TJ, Larson MG, Levy D, et al. Temporal relations of atrial fibrillation and congestive heart failure and their joint influence on mortality: the Framingham heart study. Circulation 2003;107:2920-5.

6 Ponikowski P, Voors AA, Anker SD, et al. 2016 ESC Guidelines for the diagnosis and treatment of acute and chronic heart failure: The Task Force for the diagnosis and treatment of acute and chronic heart failure of the European Society of Cardiology (ESC)Developed with the special contribution of the Heart Failure Association (HFA) of the ESC. Eur Heart J 2016:37:2129-200.

7 Rienstra M, Hobbelt AH, Alings $M$, et al. Targeted therapy of underlying conditions improves sinus rhythm maintenance in patients with persistent atrial fibrillation: results of the RACE 3 trial. Eur Heart J 2018;39:2987-96.

8 Rienstra M, Van Gelder IC, Van den Berg MP, et al. A comparison of low versus high heart rate in patients with atrial fibrillation and advanced chronic heart failure: effects on clinical profile, neurohormones and survival. Int J Cardio/ 2006;109:95-100.

9 Pathak RK, Middeldorp ME, Meredith M, et al. Long-term effect of goal-directed weight management in an atrial fibrillation cohort: a long-term follow-up study (LEGACY). J Am Coll Cardiol 2015;65:2159-69.

10 Pathak RK, Elliott A, Middeldorp ME, et al. Impact of cardiorespiratory fitness on arrhythmia recurrence in obese individuals with atrial fibrillation: the CARDIO-FIT study. J Am Coll Cardiol 2015;66:985-96.

11 Pathak RK, Middeldorp ME, Lau DH, et al. Aggressive risk factor reduction study for atrial fibrillation and implications for the outcome of ablation: the ARREST-AF cohort study. J Am Coll Cardiol 2014;64:2222-31.

12 De Maat GE, Mulder BA, Berretty WL, et al. Obesity is associated with impaired longterm success of pulmonary vein isolation: a plea for risk factor management before ablation. Open Heart 2018;5:e000771.

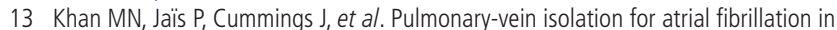
patients with heart failure. N Engl J Med 2008;359:1778-85.

14 Marrouche NF, Brachmann J, Andresen D, et al. Catheter ablation for atrial fibrillation with heart failure. N Engl J Med 2018;378:417-27.

15 MacDonald MR, Connelly DT, Hawkins NM, et al. Radiofrequency ablation for persistent atrial fibrillation in patients with advanced heart failure and severe left ventricular systolic dysfunction: a randomised controlled trial. Heart 2011;97:740-7.

16 Di Biase L, Mohanty P, Mohanty S, et al. Ablation versus amiodarone for treatment of persistent atrial fibrillation in patients with congestive heart failure and an implanted device: results from the AATAC multicenter randomized trial. Circulation 2016;133:1637-44.

17 Jones DG, Haldar SK, Hussain W, et al. A randomized trial to assess catheter ablation versus rate control in the management of persistent atrial fibrillation in heart failure. $J$ Am Coll Cardiol 2013:61:1894-903.

18 Hunter RJ, Berriman TJ, Diab I, et al. A randomized controlled trial of catheter ablation versus medical treatment of atrial fibrillation in heart failure (the CAMTAF trial). Circ Arrhythm Electrophysiol 2014;7:31-8.

19 Prabhu S, Taylor AJ, Costello BT, et al. Catheter ablation versus medical rate control in atrial fibrillation and systolic dysfunction: the CAMERA-MRI study. J Am Coll Cardiol 2017;70:1949-61.

20 Chen S, Pürerfellner $\mathrm{H}$, Meyer C, et al. Rhythm control for patients with atrial fibrillation complicated with heart failure in the contemporary era of catheter ablation: a stratified pooled analysis of randomized data. Eur Heart $J$ 2020;41:2863-73.

21 Goette A, Kalman JM, Aguinaga L, et al. EHRA/HRS/APHRS/SOLAECE expert consensus on atrial cardiomyopathies: definition, characterization, and clinical implication. Europace 2016;18:1455-90.

22 Smit MD, Moes ML, Maass AH, et al. The importance of whether atrial fibrillation or heart failure develops first. Eur J Heart Fail 2012;14:1030-40.

23 Deedwania PC, Lardizabal JA. Atrial fibrillation in heart failure: a comprehensive review. Am J Med 2010;123:198-204.

24 Nerheim P, Birger-Botkin S, Piracha L, et al. Heart failure and sudden death in patients with tachycardia-induced cardiomyopathy and recurrent tachycardia. Circulation 2004; 110:247-52.

25 Delgado V, Bax JJ. Atrial functional mitral regurgitation: from mitral annulus dilatation to insufficient leaflet remodeling. Circ Cardiovasc Imaging 2017;10.

26 Kotecha D, Lam CSP, Van Veldhuisen DJ, et al. Heart Failure With Preserved Ejection Fraction and Atrial Fibrillation: Vicious Twins. J Am Coll Cardiol 2016;68:2217-28.

27 Torp-Pedersen C, Møller M, Bloch-Thomsen PE, et al. Dofetilide in patients with congestive heart failure and left ventricular dysfunction. Danish investigations of arrhythmia and mortality on dofetilide Study Group. N Engl J Med 1999;341:857-65. 
28 Hagens VE, Van Veldhuisen DJ, Kamp O, et al. Effect of rate and rhythm control on left ventricular function and cardiac dimensions in patients with persistent atrial fibrillation: results from the RAte control versus electrical cardioversion for persistent atrial fibrillation (race) study. Heart Rhythm 2005;2:19-24.

29 Freudenberger RS, Wilson AC, Kostis JB, et al. Comparison of rate versus rhythm control for atrial fibrillation in patients with left ventricular dysfunction (from the AFFIRM study). Am J Cardiol 2007;100:247-52.

30 Roy D, Talajic M, Nattel S, et al. Rhythm control versus rate control for atrial fibrillation and heart failure. N Eng/ J Med 2008;358:2667-77.

31 Shelton RJ, Clark AL, Goode K, et al. A randomised, controlled study of rate versus rhythm control in patients with chronic atrial fibrillation and heart failure: (CAFE-II study). Heart 2009;95:924-30.

32 Al-Jazairi MIH, Nguyen B-O, De With RR, et al. Antiarrhythmic drugs in patients with early persistent atrial fibrillation and heart failure: results of the race 3 study. Europace 2021. doi:10.1093/europace/euab062. [Epub ahead of print: 26 Apr 2021].

33 Asad ZUA, Yousif A, Khan MS, et al. Catheter ablation versus medical therapy for atrial fibrillation: a systematic review and meta-analysis of randomized controlled trials. Circ Arrhythm Electrophysiol 2019;12:e007414.

34 Kheiri B, Osman M, Abdalla A, et al. Catheter ablation of atrial fibrillation with heart failure: an updated meta-analysis of randomized trials. Int J Cardiol 2018;269:170-3.

35 Sugumar H, Prabhu S, Voskoboinik A, et al. Atrial Remodeling Following Catheter Ablation for Atrial Fibrillation-Mediated Cardiomyopathy: Long-Term Follow-Up of CAMERA-MRI Study. JACC Clin Electrophysiol 2019;5:681-8.

36 Sohns C, Zintl K, Zhao Y, et al. Impact of left ventricular function and heart failure symptoms on outcomes post ablation of atrial fibrillation in heart failure: CASTLE-AF trial. Circ Arrhythm Electrophysiol 2020;13:e008461.

37 Brachmann J, Sohns C, Andresen D, et al. Atrial Fibrillation Burden and Clinical Outcomes in Heart Failure: The CASTLE-AF Trial. JACC Clin Electrophysiol 2021;7:594603.

38 Packer DL, Piccini JP, Monahan KH, et al. Ablation versus drug therapy for atrial fibrillation in heart failure: results from the CABANA trial. Circulation 2021:143:1377-90
39 Packer DL, Mark DB, Robb RA, et al. Effect of catheter ablation vs antiarrhythmic drug therapy on mortality, stroke, bleeding, and cardiac arrest among patients with atrial fibrillation: the CABANA randomized clinical trial. JAMA 2019;321:1261-74

40 Kirchhof P, Camm AJ, Goette A, et al. Early Rhythm-Control therapy in patients with atrial fibrillation. N Engl J Med 2020;383:1305-16.

41 Mulder BA, van Veldhuisen DJ, Rienstra M. What should the C ('congestive heart failure') represent in the CHA,DS,-VASc score? Eur J Heart Fail 2020;22:1294-7.

42 Verma A, Jiang C-yang, Betts TR, et al. Approaches to catheter ablation for persistent atrial fibrillation. N Engl J Med 2015;372:1812-22.

43 Winkle RA, Mead RH, Engel G, et al. High-power, short-duration atrial fibrillation ablations using contact force sensing catheters: outcomes and predictors of success including posterior wall isolation. Heart Rhythm 2020;17:1223-31.

44 Mulder BA, Luermans JGLM, Hindricks G, et al. Innovations and paradigm shifts in atrial fibrillation ablation. Europace 2021;23:ii23-7.

45 Al-Jazairi MIH, Rienstra M, Klinkenberg TJ, et al. Hybrid atrial fibrillation ablation in patients with persistent atrial fibrillation or failed catheter ablation. Neth Heart J 2019;27:142-51

46 Pison L, La Meir M, van Opstal J, et al. Hybrid thoracoscopic surgical and transvenous catheter ablation of atrial fibrillation. J Am Coll Cardiol 2012;60:54-61.

47 DeLurgio DB, Ferguson E, Gill J, et al. Convergence of epicardial and endocardial if ablation for the treatment of symptomatic persistent AF (CONVERGE trial): rationale and design. Am Heart J 2020;224:182-91.

48 Noseworthy PA, Van Houten HK, Gersh BJ, et al. Generalizability of the CASTLE-AF trial: catheter ablation for patients with atrial fibrillation and heart failure in routine practice. Heart Rhythm 2020;17:1057-65.

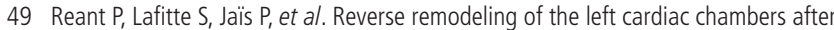
catheter ablation after 1 year in a series of patients with isolated atrial fibrillation. Circulation 2005;112:2896-903.

50 Mulder BA, Rienstra M, Blaauw Y. Evaluation and treatment of premature ventricular contractions in heart failure with reduced ejection fraction. Heart 2021;107:10-17. 